\title{
Editorial: Adding Media Reviews to Sex Roles
}

\author{
Maureen C. McHugh • Irene Hanson Frieze
}

Published online: 7 December 2011

(C) Springer Science+Business Media, LLC 2011

I have recently appointed Maureen C. McHugh to serve as Media Review Editor for Sex Roles. The Internet, and the media more broadly, are a central part of our lives today. I was pleased that Maureen was willing to take on this important task. As she explains below, the media have been of great interest to her for many years. She has some exciting ideas about how we can use this new section.

This new section begins with this issue. Under Maureen's new editorship, the media review included in this issue is a review of the film Straightlaced: How Gender's Got Us All Tied Up, a Debra Chasnoff documentary (DeRose and Composto 2011).

\section{As Dr. McHugh explains:}

Allow me to introduce myself and the section. I am a social psychologist with a commitment to teaching, and strong personal interest in popular culture. Having taught over 3,000 women in the Psychology of Women, the course I teach today is different in content, topics covered, texts and resources used, and in pedagogy from the Psychology of Women course that Irene and I team-taught in 1975. When we started teaching there were no published textbooks and very few

\footnotetext{
M. C. McHugh

Indiana University of Pennsylvania, Indiana, PA, USA

e-mail:mcmchugh@iup.edu

I. H. Frieze $(\bowtie)$

University of Pittsburgh,

Pittsburgh, PA, USA

e-mail: frieze@pitt.edu
}

articles relating to gender or to women's issues (Unger 2010). This also predates the first issues of Sex Roles published in 1975 (Frieze and Dittrich 2009). The articles we used in class were mimeographed in a garage and distributed by KNOW, a division of the National Organization of Women (NOW). (This publisher no longer operates). Now it is definitely more difficult to keep up with the texts and resources available. Hopefully the media reviews offered here will help all of us keep up.

One way to remain current and to engage contemporary students in feminist psychology is to use media and popular culture in the classroom. We hope that the Media Section of Sex Roles can contribute to teaching gender topics or courses at various levels, i.e. high school, college or graduate level classes. We are especially interested in receiving reviews of DVDs and documentaries that are designed for use in the classroom. We are also open to articles that present, describe, or evaluate classroom strategies for using media. Following tradition, the media section will include reviews of newly released films. While we hope to publish timely reviews of important newly released films and DVDs, we are also interested in reviews of TV series, televised documentaries, and commercial films. We have an expanded definition of media that includes contemporary forms of social media. Reviews of blogs, websites, on line resources, and videos are also encouraged. We hope to publish reviews of experiential exercises and educational and simulation games. We would also be interested in articles detailing uses and responses to media such as I click, d21, tweeting, and texting. If you are interested in reviewing a particular film or other materials, contact us to obtain the materials from the distributor. More information about writing a media review can be found on the 
journal's website: www.springer.com/11199. We hope to hear from you soon.

\section{References}

DeRose, L. M., \& Composto, J. B. (2011). Untying gender constraints during adolescence [Review of the film Straightlaced: How gender's got us all tied up, A Debra Chasnoff documentary, New Day Films, 2009]. Sex Roles, this issue. doi:10.1007/s11199011-0049-7

Frieze, I. H., \& Dittrich, S. (2009). Sex roles is 35! [Editorial]. Sex Roles, 62, 1. doi:10.1007/s11199-009-9720-7.

Unger, R. K. (2010). Leave no text behind: Teaching the psychology of women during the emergence of second wave feminism. Sex Roles, 62, 153-158. doi:10.1007/s11199-0099740-3. 